\title{
Persahabatan Penjajah dan Bangsa Jajahan di Hindia Belanda: C. Snouck Hurgronje dan Haji Hasan Mustapa
}

\section{JAJANG A ROHMANA}

UIN Sunan Gunung Djati Bandung

Email: jajang_abata@yahoo.co.id

\section{ABSTRACT}

This study aims to analyze the friendship between the colonizer with the colony in the Dutch East Indies. The study focuses on a number of works and letters of Haji Hasan Mustapa to C. Snouck Hurgronje. Mustapa was the Hoofd penghulu (Chief-penghulu) of Aceh and Bandung. He is a close friend of Snouck since his first met in Mecca in 1885. Through the social-intellectual history approach, the study tries to explain their closeness which are no longer merely a relationship between employer and employee, but has penetrated deeply into the true brotherhood and kinship ties. Snouck who representated as a colonial master looked Mustapa as a figure who has unique talent and character which achieve high knowledge about Islamic law and Sundanese customs. Instead, Mustapa looked Snouck as his close friends who have a commitment to defend each other. Mustapa shed his impression and expectation to meet him again someday in his letters. Mustapa often shed tears when remembering the time of togetherness that will not be forgotten throughout his life. It is an interplay friendship that have never imagined in shaping the face of colonialism in Indonesia, which its influence cannot be ignored until now.

Keywords: Snouck, Mustapa, friendship, colonizer, colony

\section{ABSTRAK}

Kajian ini bertujuan menganalisis tentang persahabatan antara penjajah dengan bangsa jajahan di Hindia Belanda. Studi ini memfokuskan pada sejumlah karya dan surat-surat Haji Hasan Mustapa pada C. Snouck Hurgronje. Mustapa adalah penghulu Aceh dan Bandung yang berteman dekat dengan Snouck sejak bertemu pertama kali di Mekah pada 1885 hingga akhir hayatnya. Melalui pendekatan sejarah sosial-intelektual, kajian ini berusaha menjelaskan kedekatan keduanya yang tidak lagi sekedar hubungan tuan dan majikan, tetapi sudah merasuk sedemikian dalam ke dalam ikatan persaudaraan sejati dan kekeluargaan. 
Snouck sebagai representasi tuan kolonial memandang Mustapa sebagai sosok yang memiliki bakat dan watak yang langka serta mencapai pengetahuan tinggi tentang syariat Islam dan adat-istiadat Sunda. Sebaliknya, Mustapa memandang Snouck sebagai sahabat dekat yang memiliki komitmen untuk saling membela di kala dekat maupun jauh. Mustapa menumpahkan pandangan dan kerinduan dirinya untuk bertemu kembali dengannya dalam surat-suratnya. Bahkan Mustapa seringkali meneteskan air mata ketika mengingat masa-masa kebersamaannya yang tidak akan terlupakan sepanjang hidupnya. Sebuah persahabatan yang tidak pernah terbayangkan dalam membentuk wajah kolonialisme di Indonesia yang pengaruhnya tidak bisa diabaikan hingga sekarang.

Kata kunci: Snouck, Mustapa, persahabatan, penjajah, bangsa jajahan

\section{PENDAHULUAN}

Sudah banyak sarjana yang mengkaji tentang peranan Christiaan Snouck Hurgronje (1857-1936) di Indonesia. Salah satu figur penting kolonial yang disebut Fogg sebagai bapak kajian Islam di Indonesia. ${ }^{1}$ la merupakan penasihat pemerintah Belanda yang pernah tinggal di Jeddah dan Mekah (1884-1885), lalu menetap lama di Hindia Belanda (18861906). ${ }^{2}$ Ia memiliki pengetahuan mendalam tentang Islam Indonesia dan dianggap berhasil dalam mempengaruhi kebijakan Belanda. ${ }^{3}$ la bahkan tetap melancarkan pengaruh yang tak putus-putusnya, walaupun samarsamar, lama setelah kepulangannya dari Indonesia tahun $1906 .{ }^{4}$

Namun, dibanding studi tentang sejarah "kesuksesan" Snouck melalui nasihat, surat-surat pribadi dan karya-karyanya, tetapi hal ini tidak diimbangi dengan kajian keterlibatan teman, sahabat dan sejumlah informannya. ${ }^{5}$ Dari dokter Abdul Ghaffar ibn 'Abdurrahman Al-Baghdadi yang banyak membantunya selama di Mekkah, Raden Aboe Bakar Djajadiningrat (1854-1914) yang banyak membantunya selama di Mekkah, ${ }^{6}$ Haji Hasan Mustapa (1852-1930) yang menyertainya berkeliling tatar Sunda dan Jawa, ${ }^{7}$ Teuku Muhamad Nurdin yang menjadi sekretaris pribadinya selama di Aceh, hingga Sayyid 'Uthman (1822-1913), mufti Betawi keturunan Arab yang cenderung akomodasionis terhadap kekuasaan pemerintah Belanda. ${ }^{8}$ Dibanding kekaguman pada Snouck, peran informan lokal cenderung diabaikan dan dipandang secara negatif karena dianggap sebagai kolaborator kolonial. ${ }^{9}$ Padahal para informan inilah yang sebetulnya ikut berperan di belakang layar dalam memudahkan Snouck untuk mendapatkan pengetahuan lokal tentang Islam di Indonesia. ${ }^{10}$ Karenanya, mereka diyakini turut berkontribusi dalam membentuk pengetahuan Snouck tentang masyarakat jajahan dan pada gilirannya 
menjadi bahan nasihat Snouck kepada pihak pemerintah Belanda.

Salah satu informan sekaligus sahabat dekat bagi Snouck adalah Haji Hasan Mustapa (1852-1930). la merupakan sastrawan Sunda terbesar dengan puluhan karya prosa dan belasan ribu bait puisi dangding Sunda. Mustapa pernah menetap di Mekah selama belasan tahun (1860-1862, 1869-1873, 1880-1885). Di Mekah pulalah awal pertemuannya dengan Snouck terjadi pada 1885 dan menyimpan kesan mendalam hingga berlanjut pada ikatan persahabatan lebih dari 40 tahun sampai akhir hayatnya pada 1930.

Kajian ini berusaha menjelaskan kedekatan di antara dua sosok penting di Hindia Belanda tersebut sepanjang peralihan abad ke-19 dan 20. Snouck sebagai sosok yang merepresentasikan wajah kolonial dan Mustapa yang mewakili pribadi bangsa jajahan yang masuk di lingkaran kolonial. Bagaimana kedekatan hubungan persahabatan yang terjalin di antara keduanya? Bagaimana pula Snouck memandang sosok informan lokal seperti Mustapa? Dan sebaliknya, bagaimana Mustapa melihat sahabat kolonialnya itu dan menumpahkan seluruh kesan-kesannya terhadap Snouck? Sumber utama kajian berupa surat-surat pribadi Mustapa kepada Snouck dan sejumlah catatan Mustapa tentang sosok Snouck dalam berbagai karya-karyanya. Dengan menggunakan pendekatan sejarah sosialintelektual, studi ini berusaha memperkuat tesis bahwa kolonialisme dan orientalisme sebagaimana dikatakan Said, mencerminkan persepsi penaklukan dan kekuasaan imperial bangsa Barat dalam menggambarkan dunia Timur. ${ }^{11}$ Tetapi persepsi tersebut dalam studi ini tidak bisa sepenuhnya dilakukan tanpa keterlibatan bangsa jajahan sebagai kolaborator kolonial. Pola hubungan kolonial dan koloni tidak hanya berupa relasi patron-klien, tuan-majikan, tetapi secara mendalam masuk ke dalam ikatan persahabatan, persaudaraan dan ikatan kekeluargaan. Kesan tersebut tergambar dalam pandangan Mustapa sebagai seorang sahabat sekaligus saudara dekat bagi Snouck.

Snouck menjadi salah satu tokoh terpenting dalam sejumlah kajian sarjana tentang studi Islam di Eropa dan sejarah kebijakan atas Islam di Indonesia. Semua seolah sepakat bahwa membahas masalah tersebut kiranya tidak absah tanpa menyebut namanya. Drewes sudah memberikan pengakuan penting sejak lama bahwa apa yang bangsa Eropa miliki sebagai ilmu pengetahuan Islam pada dasarnya adalah karya Snouck (dan Goldziher). ${ }^{12}$ Hal ini dikuatkan juga oleh studi Pedersen tentang karya- 
karya ilmiah Snouck yang dianggap sebagai guru utama (great master) dalam tradisi tersebut, salah satunya yang dikaji Brugman terkait hukum Islam. ${ }^{13}$

Namun, sosok Snouck tak hanya berpengaruh dalam pembentukan awal wajah studi Islam di kalangan orientalis Eropa, namanya juga tidak bisa diabaikan dalam sejarah kebijakan kolonial atas Islam di Indonesia, tak hanya sejak masa kolonial saja tetapi bayang-bayangnya juga masih bisa dirasakan hingga sekarang. Hal ini tergambar dalam banyak sekali kajian para sarjana. ${ }^{14}$ Mulai dari peran penting hasil foto jepretan Snouck terhadap situasi Mekah yang saat itu belum banyak diketahui, ${ }^{15}$ pengaruh besarnya terhadap kebijakan Belanda dalam menangani perang Aceh, ${ }^{16}$ serta peletak dasar-dasar kebijakan tentang Islam di Hindia Belanda dari berbagai sisinya, baik dilihat dari kepentingan kolonial, keturunan Arab, penghulu, debat kontemporer tentang kesesuaian Islam dan modernitas yang tidak lepas dari gambaran Islam sebagai agama dalam karya Snouck, hingga penggunaan lensa Arab oleh Snouck dalam memandang Hindia Belanda. ${ }^{17}$ Selain itu, para sarjana juga tak hanya memujinya, sejumlah suara kritis terhadap Snouck juga disampaikan, misalnya oleh Benda, Waardenburg dan Wertheim dan van Dijk terkait kebijakan kolonial yang mengandung sejumlah kontradiksi. ${ }^{18}$

Studi ini merupakan kelanjutan dari kajian tentang peran penting informan dan kolaboratornya yang ditarik Snouck ke dalam lingkaran kolonisasi kolonial atas Islam, ${ }^{19}$ tetapi signifikansi informan seperti Mustapa dalam kajian ini diulas dengan menggambarkan kedekatan keduanya yang sangat intim secara personal melalui surat-surat pribadi Mustapa, baik sebagai bawahan, sahabat bahkan saudara dekat.

\section{HUBUNGAN SNOUCK DENGAN MUSTAPA}

Sebagaimana diketahui, Snouck dianggap sebagai penasihat kolonial paling berpengaruh dalam sejarah kolonial di Nusantara. la dianggap salah seorang sarjana Belanda yang menandai periode penting kolonisasi pengetahuan di Hindia Belanda yang dijadikan sebagai bagian dari alat penjajahan. Di awal karirnya, Snouck berhasil memasuki Mekah untuk mengetahui sisi terdalam Islam dan masyarakat Muslim. ${ }^{20}$ la dikirim ke Mekkah sekitar selama enam bulan (1884-1885), lalu ke Hindia Belanda sekitar delapan belas tahun (1889-1906), tak lama setelah banyaknya upaya perlawanan ulama lokal seperti tampak pada perang Jawa/Diponegoro 
(1825-1830), perang Aceh (1873-1912) dan pemberontakan di Banten (1888). ${ }^{21}$ Ini menguatkan pandangan adanya upaya kolonial untuk lebih memahami kondisi masyarakat jajahan demi menjaga kelangsungannya. Sosok Snouck sebagai penasihat Belanda untuk urusan pribumi (adviseur voor inlandsche zaken) dianggap berhasil dalam mempengaruhi kebijakan Belanda. ${ }^{22}$ la memahami budaya Indonesia dan yakin bahwa Barat memiliki nilai untuk diberikan pada orang Nusantara. Ia berusaha memberikan pencerahan agar mereka memahami apa yang budaya Barat bisa lakukan bagi mereka. ${ }^{23}$

Haji Hasan Mustapa berada dalam lingkaran kehidupan Snouck tersebut selama karirnya di Hindia Belanda. Sejak bertemu dengan Snouck di Mekkah sekitar tahun $1885^{24}$ dan berlanjut ketika di Hindia Belanda (18891906), Mustapa terus-menerus menjalin kontak dengan Snouck melalui surat berbahasa Arab. ${ }^{25}$ Keduanya diyakini mengembangkan kemampuan bahasa Arab selama di Mekah. Kedekatan keduanya selama di Mekah mulai terbangun tidak saja didasarkan pada keyakinan sebagai saudara sesama Muslim, ${ }^{26}$ tetapi juga kerja keras Snouck dalam melakukan studi antropologis komunitas Jawi di Mekah secara mendalam, tempat di mana Mustapa tergabung di dalamnya.

Hubungan awal persahabatan tersebut menyimpan kesan mendalam bagi Snouck untuk kemudian membuat janji agar bisa bertemu di Hindia Belanda. Empat tahun kemudian tepatnya tahun 1889, Snouck tiba di Hindia Belanda. la kemudian bertemu kembali dengan Mustapa. Van Koningsveld menegaskan bahwa tak lama setelah tiba di Hindia Belanda, Snouck menikah dengan gadis Sunda bernama Sangkana (w. 1896) di Ciamis. Dari Sangkana, Snouck dikaruniai empat anak: Salmah Emah, Umar, Aminah dan Ibrahim. Setelah Sangkana meninggal dunia pada tahun 1896, Snouck kemudian menikahi Siti Sadijah (1885-1974) pada tahun 1898. Ia merupakan putri R.H. Muhamad Su'eb yang terkenal dengan Kalipah Apo, wakil Penghulu Bandung Haji Hasan Mustapa. Darinya Snouck dikaruniai seorang anak yaitu R. Jusuf. ${ }^{27}$ Dilihat dari kedekatannya dengan Mustapa selama di Priangan dan Batavia ditambah jabatan Mustapa sebagai Hoofd Penghulu Bandung sejak 1896, bisa dipastikan Mustapa hadir dan memiliki peran besar dalam pernikahan Snouck dengan kedua gadis Sunda tersebut.

Kedekatan Snouck dan Mustapa selanjutnya tergambar dalam perjalanannya berkeliling daerah Sunda dan Jawa selama dua kali. Dalam sejumlah puisinya, Mustapa menceritakan bahwa dirinya diajak oleh 
Snouck untuk berkeliling Jawa. Perjalanannya ke Jawa menurut keterangan van Ronkel terjadi tahun 1889-1891. ${ }^{28}$ Keduanya berkeliling Jawa dua kali dalam dua tahun, dari pertengahan Juli 1889 sampai awal Februari 1891. la mengunjungi banyak tempat di Ponorogo, Madiun, Surakarta, Yogyakarta, Magelang, termasuk sejumlah pesantren. ${ }^{29}$

Mustapa kemudian menceritakan bahwa selepas perjalanannya ke Jawa, ia banyak menyalin berbagai primbon, kitab, pusaka dari Jawa yang kemudian diserahkan kepada Snouck. ${ }^{30}$ Ketika mendengar laporan tentang buku-buku tasawuf yang digunakan di Kendal pada 1886, Mustapa menyatakan karya-karya tersebut dimaksudkan untuk memelihara perilaku lahir dan batin yang baik bagi pembacanya. Selama bekerja pada Snouck, Mustapa dibayar $f 50$ perbulan. la mengumpulkan daftar karya berbahasa Arab di Priangan kepada pemerintah pada Nopember 1889. Banyak di antara yang dikumpulkannya merupakan teks Shattariyah. ${ }^{31}$ Di sini tampak bahwa Mustapa mengetahui banyak tentang ajaran Shattariyah dan martabat tujuh, tidak saja dari sejumlah guru yang ditemuinya terutama di Mekah, tetapi juga melalui sejumlah naskah yang ditemukannya.

Sepulangnya dari Jawa, hubungan keduanya berlanjut ketika Snouck pergi ke Aceh (Juli 1891-Februari 1892) lalu mengusulkan pengangkatan Mustapa kepada Gubernur Aceh tertanggal 26 Oktober 1892 untuk menjadi penghulu di Kutaraja Aceh setelah menyisihkan calon penghulu asal Pontianak. Snouck tidak pernah bertemu selama Mustapa menjadi penghulu di Aceh sekitar dua tahun sembilan bulan pada Maret 1893Januari 1896. la menjalin komunikasi dengan Mustapa melalui surat. Hampir setiap pekan Mustapa berkirim surat kepada Snouck di Batavia.

Ketika Mustapa pindah menjadi penghulu di Bandung pada 1896, Snouck juga tetap menjaga komunikasi dengan Mustapa, boleh jadi Mustapa dan Snouck saling berkunjung antara Bandung dan Batavia. Mustapa menjadi penghulu Bandung tahun 1896-1917. Snouck akhirnya kembali ke Belanda tahun 1906. Mustapa tetap menjalin komunikasi dengan Snouck di Belanda yang bertempat tinggal di Witte singel 84 a Leiden. Korespondensi pun terus berlangsung sampai Mustapa pensiun sebagai penghulu Bandung tahun 1917 bahkan hingga beberapa tahun sebelum Mustapa meninggal.

Berikut data dan peristiwa yang dialami Snouck dan Mustapa yang mencerminkan hubungan erat di antara keduanya diolah dari sejumlah sumber: 


\begin{tabular}{llll}
\hline \multicolumn{1}{c}{ C. SNOUCK HURGRONJE } & \multicolumn{2}{c}{ HAJI HASAN MUSTAPA } \\
\hline Lahir di Belanda & 1857 & 1852 & Lahir di Garut \\
\hline Pergi ke Mekah & 28 Agustus 1884-1885 & $\begin{array}{l}1860-1862,1869-1873, \\
1880-1885\end{array}$ & Pergi ke Mekah \\
\hline Bekeliling Jawa & $1889-1891$ & $1889-1891$ & $\begin{array}{l}\text { Berkeliling } \\
\text { Jawa }\end{array}$ \\
\hline $\begin{array}{l}\text { Menikahi Sangkana } \\
\text { (w. 1895) di Ciamis }\end{array}$ & 1890 & 1890 & $\begin{array}{l}\text { Kemungkinan } \\
\text { hadir }\end{array}$ \\
\hline $\begin{array}{llll}\text { Bertugas di Aceh } \\
\text { Weltevreden }\end{array}$ & Juli 1891-Pebruari 1892 & $\begin{array}{l}\text { Maret 1893-Januari } \\
1896\end{array}$ & $\begin{array}{l}\text { Bertugas di } \\
\text { Aceh }\end{array}$ \\
\hline $\begin{array}{l}\text { Menikahi Siti Sadijah } \\
\text { (w. 1974) di Bandung }\end{array}$ & 1898 & $1896-1917$ & $\begin{array}{l}\text { Penghulu } \\
\text { Bandung }\end{array}$ \\
\hline $\begin{array}{l}\text { Kembali ke Belanda } \\
\text { Menikahi Ida Maria }\end{array}$ & 1906 & 1898 & $\begin{array}{l}\text { Kemungkinan } \\
\text { hadir }\end{array}$ \\
$\begin{array}{l}\text { Oort di Belanda } \\
\text { Meningal }\end{array}$ & 1910 & 1917 & Pensiun \\
\hline
\end{tabular}

Kedekatan Mustapa dengan Snouck tidak dapat diabaikan, karena sangat berpengaruh terhadap perjalanan hidup Mustapa sebagai seorang elite pribumi dengan jabatan Hoofd Penghulu Aceh dan Bandung yang pada gilirannya berpengaruh pula terhadap kedekatan keduanya seperti tergambar dalam surat-surat dan karya-karyanya. Otoritas yang dimiliki Mustapa sebagai penghulu dalam birokrasi administrasi kolonial memungkinkannya bisa mengakses banyak informasi dari berbagai sumber. ${ }^{32}$

Bagi Snouck, ia menjadi salah satu tokoh kunci yang membuka informasi untuk memperoleh pengetahuan tentang Islam lokal termasuk dunia tarekat. ${ }^{33}$ Kontak pribadinya sekali lagi membuka mata Snouck tentang para pelaku tarekat dan memberinya alasan untuk berpikir ulang, atau paling tidak untuk memperlembut dugaan dia sebelumnya tentang 'bahaya' tarekat di masyarakat terutama pasca peristiwa Cilegon 1888 atau yang dikenal sebagai pemberontakan 'petani Banten'. ${ }^{34}$ Snouck sendiri akhirnya mengaku pernah dibaiat dalam tarekat. Karyanya De Atjehers (1893) seakan mengembalikan jejak silsilah tarekat Shattariyah yang ditemuinya di Jawa Barat sampai kepada 'Abdurrauf. ${ }^{35}$

Keintiman Mustapa dan Snouck merupakan kelanjutan dari kedekatan sosok K.F. Holle (1829-1896), penasihat Belanda sebelumnya dengan Raden Moehamad Moesa (1822-1886), penghulu Limbangan. ${ }^{36}$ Dengan latar belakang ménak dan santri, Mustapa diusulkan Snouck untuk menjadi elite penghulu Aceh dan Priangan sekaligus masuk ke dalam lingkaran 
kaum ménak dan pada gilirannya lingkaran kolonial. ${ }^{37}$

Mustapa menjadi Hoofd Penghulu di Kutaraja, Aceh atas desakan Snouck kepada Gubernur Militer dan Sipil Acéh, Jenderal Deykerhoff. Menurut Snouck dalam suratnya kepada Gubernur Jenderal Hindia Belanda tanggal 8 Maret 1896, tidaklah mudah dia membujuk Mustapa supaya mau menduduki jabatan tersebut. Ia menjadi Hoofd Penghulu Kutaraja selama sekitar dua tahun sembilan bulan (1893-1895). Mustapa menerima karena menghargai persahabatannya dengan Snouck. Namun karena ketidakcocokkan dengan para pejabat Belanda di Aceh, Mustapa akhirnya memilih pindah menjadi Hoofd Penghulu Bandung. ${ }^{38}$

Hubungan Mustapa dan Snouck pada dasarnya mencerminkan visi masa depan kolonial di wilayah jajahan seperti tampak dalam fatwa Mustapa tentang pemerintah kolonial di Aceh. ${ }^{39}$ Bahkan mungkin lebih dari itu, Mustapa tidak saja berperan banyak dalam pembentukan pemahaman Snouck tentang kondisi aktual sosial-politik dan budaya lokal pada masanya, termasuk menyediakan banyak salinan naskah lokal yang dibawa Snouck atau dikirim melalui jasa pos. Bahkan Mustapa boleh jadi paling banyak mengetahui kehidupan pribadi dan keluarga Snouck di Hindia Belanda. Sesuatu yang sejak lama disembunyikannya dan sempat memicu kontroversi di kalangan para sarjana. ${ }^{40}$

Semua informasi dan kontak Mustapa dengan Snouck umumnya disampaikan Mustapa melalui kiriman karangan dan surat-surat pribadi kepada Snouck. Sejumlah karya Mustapa seperti Adji Wiwitan Istilah dan beberapa dangding juga di beberapa bagian memuat komentar dan ungkapan Mustapa tentang sosok Snouck. Selain itu, sejumlah surat-surat Mustapa yang disimpan di UB Leiden dengan kode Or. 8952 dan Or. 18.097 juga memuat berbagai ungkapan Mustapa tentang pribadi Snouck.

\section{MUSTAPA DI MATA SNOUCK}

Untuk mengungkap pandangan Mustapa tentang Snouck, penting kiranya terlebih dahulu menggali pandangan Snouck tentang Mustapa. Boleh jadi Snouck turut membaca penilaian atas dirinya dan memberikan tanggapan atas sosok Mustapa sebagaimana tampak dalam surat-suratnya kepada pemerintah Belanda. Berikut gambaran bagaimana Snouck memiliki kesan baik terhadap pribadi Mustapa seperti tergambar dalam nota bertanggal 22 Mei 1922 yang dikirim kepada sekretaris pemerintah di Buitenzorg, jelang penunjukan Mustapa sebagai penghulu Aceh: 
Haji Hasan Mustapa telah saya kenal dari dekat sejak kurang lebih 10 tahun dan selama waktu itu rasa hormat saya terhadap watak dan bakatnya yang benar-benar langka, semakin bertambah. Pemukimannya selama 13 tahun di negara Arab - tempat saya berkenalan dengan dia - didahului oleh telaah beberapa tahun di Priangan, kampung halamannya, telah menyebabkan ia mencapai tingkat yang luar biasa tingginya mengenai syariat Islam untuk daerah-daerah ini. Di negara Arab maupun sesudah ia pulang ke kampung halamannya pada tahun 1885, ia seorang guru yang dihormati dan dicintai. Beberapa karya telah diterbitkannya dalam bahasa Arab. ${ }^{41}$

Snouck menyebutkan bahwa ia sudah kenal dekat dengan Mustapa sekitar 10 tahun. Ini boleh jadi dihitung sejak Snouck tiba di Hindia Belanda dan pergi berkeliling Jawa antara 1889-1891 lalu keduanya semakin sering bertemu hingga jelang kepulangannya ke Belanda pada 1906. Saat itu Mustapa sudah menjadi Hoofd Penghulu Bandung hingga 1917.

Ungkapan penghormatan Snouck atas bakat dan watak Mustapa dalam kutipan di atas tergambar jelas. Snouck bahkan menyebut kemampuan Mustapa sudah mencapai tingkat yang luar biasa tingginya mengenai syariat Islam untuk daerah-daerah ini (Sunda). Boleh jadi penilaian Snouck atas sosok Mustapa tersebut didasarkan pada sejumlah karya-karya Mustapa terutama tentang adat-istiadat Sunda.

Karangan Mustapa tentang adat-istiadat Sunda terdiri dari dua macam, yang besar dan kecil, yakni Bab Adat² Oerang Priangan Djeung Oerang Soenda Lian ti Eta (Bab adat-adat orang Priangan dan orang Sunda lainnya) dan Buku Leutik Pertelaan Adatna Jalma-jalma di Pasundan (Buku kecil menjelaskan adatnya orang-orang di Pasunda). Naskah asli yang besar disimpan di UB Leiden diberi kode LOr. 7695.42 Lalu dipublikasikan di kantor cetak pemerintah di Betawi pada 1913.43 Karena dianggap sangat penting, karya ini kemudian diterjemahkan ke bahasa Belanda oleh sastrawan Sunda R. Memed Sastrahadiprawira (1897-1932), tetapi keburu meninggal. Penerjemahannya dilanjutkan oleh R.A. Kern hingga terbit tahun 1946.44 Buku ini juga diterjemahkan ke dalam bahasa Indonesia oleh M. Maryati tahun $1985 .{ }^{45}$

Sedangkan buku kecil berjudul Buku Leutik Pertelaan Adatna Jalmajalma di Pasundan diterbitkan sekitar tiga tahun kemudian 1916. Buku yang kecil tersebut menjadi pengantar untuk buku yang besar tentang adat-istiadat Sunda. Buku kecil tersebut diterbitkan oleh Lembana 
Wignjadisastra, anak perempuan Mustapa dari istri yang ketiga, Rd. Ratna (lyoh), melalui penerbit Tjahaja Pasoendan Bandung. ${ }^{46}$ Baik buku besar maupun buku kecil Mustapa tentang adat-istiadat Sunda hingga sekarang masih digunakan sebagai rujukan karena dianggap studi etnografis budaya Sunda paling lengkap dan mendalam.

Kekaguman Snouck atas sosok Mustapa juga tampak dari ungkapannya bahwa Mustapa dianggap sebagai seorang guru yang dihormati dan dicintai baik di Mekah maupun di kampung halamannya. Penilaian Snouck tentu didasarkan oleh pandangan mata kepalanya sendiri sejak bertemu dengannya pada 1885. Berikut pandangan Snouck tentang sosok Mustapa ketika di Mekah:

Hasan Mustafa was Muhammed's pupil in Java, and came first to Mekka about 14 years ago, to hear the lectures of the elder Jâwah divines and to attend in the Haram the lectures of Hasab Allah, Mustafa 'Afîfi, Abdullah Zawâwî etc. For about ten years he has taught himself, and some of the text-books written by him, (including one on Arabic prosody) have been published in Cairo. In his house, one always found after sunrise and in the afternoon, several dozens of Javanese and Sundanese, listening to his words: at other times he studies himself in the Haram. A few years ago he returned to Java, not meaning however to stay longer there than to put his affairs in order.

Artinya: Hasan Mustapa merupakan murid Muhammad (Garut) di Jawa, dan datang pertama kali ke Mekah sekitar 14 tahun lalu, untuk mendengar ceramah dari (ulama) Jawah yang hebat dan lebih tua dan untuk hadir di (Masjidil) Haram mendengarkan ceramah Hasab Allah, Mustafa 'Afîfi, Abdullah Zawâwî dan lainnya. Sekitar sepuluh tahun, Mustapa belajar dan beberapa teks buku ditulis olehnya, (termasuk satu buku tentang syair Arab) sudah diterbitkan di Kairo. Di rumahnya, selepas matahari terbit dan di sore hari, selalu ditemui beberapa lusin orang Jawa dan Sunda mendengarkan kata-katanya. Di saat yang lain, ia juga belajar di Masjidil Haram. Sekitar beberapa tahun lalu, ia kembali ke Jawa, tetapi bukan berarti tinggal selamanya di sana selain untuk menyelesaikan urusannya dengan baik. ${ }^{47}$

Penilaian Snouck tersebut selain membuktikan pertemuan dirinya dengan Mustapa di Mekah, juga menggambarkan kekaguman Snouck atas sosok Mustapa sebagai satu di antara dua orang Sunda yang menarik perhatian dirinya karena dikelilingi oleh anak-anak muda yang belajar 
padanya, selain dirinya juga belajar pada sejumlah ulama Mekah. Snouck bahkan menyebut Mustapa sudah menerbitkan buku di Kairo, salah satunya tentang persajakan atau syair Arab. Sebuah kemampuan yang tidak banyak dimiliki para ulama Jawah yang berasal dari Sunda.

Kesan Snouck juga tampak ketika menceritakan pengalaman kebersamaannya dengan Mustapa selama berkeliling Jawa. Mustapa dalam penilaian Snouck sudah sangat dikenal dan memiliki nama baik di seluruh pulau Jawa.

Secara pribadi saya harus mengakui bahwa saya merasa senang tokoh tersebut (Mustapa) menjadi teman seperjalanan dalam perjalananperjalanan awal saya di Pulau Jawa. Saya banyak berutang budi karena pengalamannya yang kaya dan banyaknya hubungan yang telah didapatnya berkat nama baiknya di seluruh Pulau Jawa. Semua tawaran untuk dimasukkan dalam golongan ulama resmi selalu ditolaknya. Alasannya sama dengan alasan yang sampai sekarang masih menjadi halangan bagi orang lain yang mendapat kedudukan tertentu di dalam masyarakat pribumi berkat kemajuannya sendiri dalam menerima pangkatpangkat seperti itu. Perlakuan sebagai penghulu yang sering mereka alami dari pihak orang Eropa, jelasnya banyak mengurangi kehormatan yang sebelum itu biasa mereka nikmati. ${ }^{48}$

Kesan Snouck terhadap Mustapa di atas menggambarkan kedekatannya sebagai sahabat yang sudah mengenal kepribadiannya sejak lama. Kedekatan ini semakin jelas ketika kita sebaliknya juga membaca penilaian dan ungkapan kerinduan Mustapa atas Snouck.

\section{SNOUCK DAN UNGKAPAN KERINDUAN MUSTAPA}

Sebagai seorang sahabat dekat, Mustapa mengungkapkan pengalaman dan penilaian dirinya tentang Snouck dalam sejumlah karangannya. Ia misalnya, mengungkapkan kesannya terhadap Snouck yang dianggapnya sebagai sahabat dekat yang saling membela selamanya. Mustapa menceritakan bagaimana kesannya terhadap sosok Snouck dalam salah satu karangannya Adji Wiwitan Istilah:

"...bangsa Eropah nu pangkat Profesor Doktor, saperti ieu nu maparin surat sértipikat dulur kaula geus 40 taun...C. Snouck Hurgronje, sarta kabaca kapujian kaula, ti sobat raket, nu sili bélaan salawasna keur deukeut keur jauh, sanajan papisah jauh, sabaraha anggangna ti Kaum Bandung tanah Priangan, Jawa, ka Leiden, tanah 
Nederland Eropah, kajeun wayahna baé da geus sili bélaan, sili cekelan ditambah ku tedak dipikanyaah ku Belanda. ${ }^{49}$

Artinya: "...bangsa Eropa yang bertitel Profesor Doktor, seperti yang mengirim surat ini adalah saudara saya berjalan sudah 40 tahun... C. Snouck Hurgronje, serta terbaca sanjungan saya, ia sahabat dekat, yang saling bela selamanya ketika dekat dan jauh, meski terpisah jauh seberapa jauhnya dari Kaum Bandung tanah Priangan Jawa ke Leiden tanah Netherlands Eropa. Meski begitu sudah mesti saling bela, saling memegang (janji) ditambah saya aslinya memang disayangi oleh Belanda."

Ungkapan Mustapa tersebut menggambarkan bagaimana keduanya berjanji untuk saling membela. Keduanya memang pernah mengalami kejadian di mana Snouck dan Mustapa masing-masing merasa berhutang karena mendapatkan pembelaan. Snouck misalnya, konon dikabarkan mendapatkan pembelaan Mustapa saat Snouck diselamatkan Mustapa di Mekah karena dituduh sebagai mata-mata. Begitu juga Mustapa mendapatkan pembelaan Snouck, saat Mustapa menjabat sebagai Hoofd Penghulu Aceh dianggap "berat sebelah" dan "tidak selalu terpercaya." Snouck membela Hasan Mustapa dalam sebuah nota, tertanggal Betawi, 22 Mei 1894. Nota tersebut telah disampaikannya kepada Sekretaris Pemerintah di Buitenzorg. ${ }^{50}$ Membaca nota pembelaan Snouck atas Mustapa, tampak jelas kepercayaan besar yang diberikan Snouck kepada Mustapa dalam kasus alasan kepindahan Mustapa dari Aceh pada 1896 setelah merasa tidak cocok dengan Asisten Residen Aceh Besar.

Kepercayaan dan kecintaan sahabat koloni seperti Mustapa kepada tuannya juga banyak tergambar dalam surat-surat pibadi Mustapa kepada Snouck terutama Or. 8952. Kumpulan surat-surat ini berjumlah sekitar 18 surat yang ditulis dalam rentang waktu sekitar 1894-1923. Dalam suratsurat Mustapa tersebut, Snouck sudah dianggap Mustapa seperti saudaranya sendiri. Kadang Mustapa menunjukkan kerinduan untuk bertemu dengan saudaranya itu (min al-akh al-'ashiq li muwajahah akhih). ${ }^{51}$ Sebuah ungkapan kerinduan Mustapa yang berada jauh dari sahabatnya itu ribuan kilometer jaraknya antara Bandung dan Belanda di Eropa. Tampak jelas kerinduan hati Mustapa dalam surat-suratnya ini kepada Snouck yang disebutnya sebagai saudara lama dan teman setia (al-akh al-qadim wa alrafiq al-qawim). ${ }^{52}$ Kiranya begitu pula Snouck dalam surat-surat balasannya yang tidak diketahui entah kemana setelah sampai di tangan Mustapa. 
Berikut sebagian ungkapan kerinduan Mustapa dalam surat-suratnya.

Dalam suratnya tanggal 1 Januari 1911, Mustapa mengungkapkan perasaan hatinya yang bertanya-tanya kapan dan kapan lagi dirinya dipertemukan kembali dengan Snouck. Surat ini ditulis sekitar lima tahun setelah kepulangan Snouck ke Hindia Belanda tahun 1906:

"Kita menjalani hidup dan berpisah dalam hitungan tahun. Pikiranku lelah dan pandanganku kering. Kapan, kapan (lagi) kita saling menyayangi sebagaimana masa lalu dalam kehidupan yang berkecukupan dan keteraturan yang penuh hormat dalam kesehatan. "53 Masih dalam surat yang sama, Mustapa tampak berharap seandainya Snouck yang sudah dianggap saudaranya itu datang lagi ke Jawa demi hembusan keharuman, sentuhan ruhani dan kebahagiaan hatinya:

"Nafsu kemanusiaan sudah saya lalui, sampai-sampai saya berpikir dengan perandaian ribuan perandaian. Terlintas di pikiran saya, seandainya engkau datang ke Jawa dalam waktu dekat dan meski dengan sedikit paksaan, keringanan dan perubahan udara agar menghembuskan kepada saya dengan hembusan keharuman dan sentuhan ruhani dan kebahagiaan hati dan indahnya kebaikan. Saya tidak tahu bagaimana kabar sahabat-sahabatmu selain saya. Keselamatan atasmu dan khususnya untuk orang yang berada di rumahmu. Terutama "yang segelnya dari kesturi, ... maka hendaknya mereka berlomba-lomba. "54

Dalam surat lainnya tanggal 23 Februari 1911, Mustapa kembali mengungkapkan kerinduannya tersebut. Kali ini dengan bahasa kerinduan yang cukup jelas disampaikan Mustapa sebagai balasan kerinduan yang juga diungkapkan Snouck.

"Saya memahami isi surat engkau berisi suatu (ungkapan) halus.

Di antara pendahuluan beritanya adalah mengenai berita kerinduan. Demikianlah ia sudah memenuhi hati saya selamanya karena rindu. "55

Dalam surat lainnya tanggal 27 Januari 1912, Mustapa bahkan membayangkan dirinya dan Snouck berkumpul dan berbincang bersama setelah makan di Parapatan. Tak diketahui daerah yang dimaksud, tetapi kiranya ia merupakan sebuah tempat yang boleh jadi pernah disinggahi keduanya dan menyimpan kenangan yang tak pernah bisa dilupakan:

"Di antara berita lainnya, sebagaimana biasa saya menulis surat ini dan menceritakan semua di dalamnya padamu dengan niat ikhlas meski pun tiada guna. Seolah saya dan engkau berkumpul dan berbincang 
setelah makan di Parapatan, kalaupun mereka menertawakan apa yang dilihatnya, demi menjaga persaudaraan sebelumnya selamanya." 56 Bahkan dalam suratnya tanggal 29 Maret 1912, Mustapa mengenang kisah ketika untuk terakhir kalinya dirinya berpisah dengan Snouck saat mengantarkannya ke Pelabuhan Tanjung Priok pada malam hari tanggal 31 Maret 1906 untuk berlayar pulang kembali ke negeri Belanda:

"Demikianlah saya tulis semuanya, sekalipun "sia-sia" saja. Karena itu semua kabar yang diminta olehmu. Dan karena saya teringat di malam perpisahan di Tanjung Priok antara saya dan engkau pada 31 Maret di kapal uap. Saya kirimkan untuk menunjukkan kesehatan walafiat. Saya harap Tuan ada juga demikian, bahkan lebih sehat dari saya. "57

Ungkapan senada disebutkan Mustapa dalam surat tanggal 13 September 1912 bahwa dirinya berharap rasa cinta dan persaudaraannya tidak terputus, walau tiupan angin topan menghapus kebaikan dan bau harumnya.

"Karena yang diharap hanyalah supaya tidak terputusnya rasa cinta dan persaudaraan yang tidak pantas dari sisi saya menerbangkan surat ini sesuai tempatnya, walau tiupan angin dan topan menghapus kebaikan dan bau harumnya. Saya senang sekali mendapat suratmu yang panjang dengan kabar sehat walafiat, walau dengan penundaan, semoga Tuan membalas engkau dengan yang utama. Saya membalasmu sekarang dengan sebagian yang diminta itu. "58

Dalam suratnya yang lain 25 Oktober 1913, Mustapa mengungkapkan kekagumannya dengan rencana Snouck untuk pergi ke Amerika. Mustapa mengungkapkan kekagumannya atas negeri itu dengan bahasa Arab puitis, berharap agar Snouck bisa berbagi kebahagiaan dan mendoakannya agar bisa lancar. Di sini kita bisa melihat kemahiran Mustapa dalam menggunakan bahasa Arab yang indah.

"Saya juga melihat dalam surat kabar bahwa engkau hendak pergi ke Amerika. Sebuah negeri yang terkenal makmur, bebas dan berpengetahuan, Dengan keindahan duniawi dan hati, perhiasan yaqut dan permata, simpanan kekayaan yang tampak dan hasil sentuhan yang bersinar bagi pandangan mata, padanya ada bangunan yang menakjubkan dan keluar semerbak harum dan wangi. Padanya keluar tanda-tanda (ayat) surat al-Rahman. Inilah surat untuk saling sapa dan keramahan antara kita. Saya harap engkau sukses dan beruntung. 
Perjalanan wisata yang baik. Saya harap darimu kemurahan hati. Engkau kirimkan pada saya sesuatu yang mengagumkan dari Amerika yang menakjubkan. Hingga saya (seperti) bisa menyaksikan bangunan yang nyata secara langsung. "59

Ungkapan kerinduan Mustapa untuk bertemu dengan Snouck, diungkapkan juga oleh Mustapa dalam surat berikutnya tanggal 12 Agustus 1915.

"Di antaranya, jelas bagimu bahwa saya dan engkau saling bersaudara, berteman jauh atau dekat, hadir atau tidak, tersembunyi atau tampak, Kemampuan dan kondisi saya berkurang dengan kemestian adanya perubahan waktu, maka tidak berubah dalam hati selain rasa rindu dan keinginan untuk bertatap muka secara sempurna dan perbincangan di antara kita dalam kesehatan sekarang ini. "60

Hubungan persahabatan yang erat dan penuh kenangan itu tampak juga dari rasa sedih yang menghinggapi keduanya dalam surat 6 Mei 1916. Snouck di Belanda mengungkapkan rasa sedih dan penyesalan. Mustapa di Bandung juga mengungkapkan rasa berat hati menghadapi situasi yang dihadapinya, hingga menetes air matanya ketika membaca keinginan kuat Snouck untuk bercita-cita datang kembali ke Jawa. Sebuah keinginan yang bukan tanpa alasan bila mengingat keluarga dan sahabat yang ditinggalkannya jauh di Hindia Belanda.

"Saya membacanya secara langsung hasilnya kabar tentang sebagian kesehatanmu bercampur dengan kesedihan dan penyesalan. Sebagaimana saya membacanya, di bagian akhir surat itu disertai ketetapan dan pengetahuanmu untuk mempengaruhi hati dan semangat menghadapi buruknya perkara duniawi sebagaimana adanya. la merupakan sifat yang biasa dalam hati dan wujud saya setelah selama setahun kita tidak terpisah, khususnya ketika saya membaca kalimat kerinduan dan rasa berat hati karena kekosongan ruang (hati) dan sudut yang terlupakan. Yaitu seperti halnya di Goa Thur atau Masjid Sela. Hingga tidak ada lagi yang mendekat ke tempat tersebut dari orang yang menginginkan (terhindar) dari kekacauan situasi dan pikiran. Jatuhlah dan menetes air mata saya ketika membaca kalimat bertambahnya kecenderungan hati dan cita-cita ke ujung Jawa. Setelah itu, jadilah kesungguhan itu perpisahan yang panjang. Saya bergembira sekali bila engkau bermaksud mewujudkan tujuan itu seperti seharusnya." 61 
Akhirnya, ungkapan kerinduan Mustapa atas sahabat dekatnya Snouck diungkapkan dalam surat tanggal 21 Juli 1917. la membayangkan dudukduduk bersama Snouck dan saling mengungkapkan berbagai pemikiran. Bila ada yang menyapa dan bertanya maka akan dijawab Mustapa dengan penuh perasaan kehilangan. Mustapa berharap bisa terbang dengan ruh di keharuman taman surga bersama kembali ke tempat yang kekal.

"Di antara hal yang membanggakan, masih bolehnya di antara dua saudara untuk saling bermurah hati. Saya membayangkan dalam hati duduk-duduk antara saya dan engkau di sebuah tempat di mana kita mengungkapkan berbagai pikiran kita. Mereka bertanya pada kita, bagaimana kabarmu? Saya jawab, baik. Bagaimana istirahatmu? Saya jawab, sesuai dengan perasaan kehilangan saudaranya. Bagaimana tanah dan kebunmu? Saya jawab, baik, saya tanam dan berbuah berbagai macam buah, apa yang engkau harapkan sesudah itu. Saya harap kita bepergian, menyaksikan dan terbang dengan ruh dan keharuman di surga yang penuh kenikmatan. Saya tidak mati kecuali setelah mencium bau harum pertemuan itu sebelum kembali ke tempat yang kekal." "62

Demikian pandangan dan ungkapan kerinduan Mustapa sebagai teman dan sahabat Snouck yang dengan setia berkirim surat sejak pertemuan pertamanya 1885 hingga jelang akhir hayatnya. Puluhan tahun persahabatannya menyimpan kesan dan kenangan yang tidak mudah terlupakan. Terlebih keluarga Snouck, istri dan anak-anak tercinta yang ditinggalkan di Priangan, selalu menghantui ingatan Snouck yang tinggal jauh ribuan kilometer di Eropa. Kiranya hanya Mustapa yang bisa diharapkan dan dengan setia mengabarkan segala keadaan yang dialami mereka. Karenanya, hubungan Snouck dan Mustapa di sini tidak lagi sekedar majikan dengan tuan kolonialnya atau sebagai informan dan sahabat setia, tetapi juga sudah masuk ke dalam hubungan keluarga di mana Snouck sudah dianggap menjadi bagian dari keluarga besar menak Priangan. Dan Mustapa menjadi penghubung dan pengikat ikatan kekerabatan itu.

\section{KESIMPULAN}

Studi Islam di Indonesia era kolonial tidak bisa dilepaskan dari nama C. Snouck Hurgronje. Namanya menandai periode kolonisasi pengetahuan yang dijadikan alat penjajah dalam membentuk wajah bangsa jajahan. 
Namun dalam upaya kolonisasi tersebut bangsa penjajah tidak bisa melepaskan dari peran penting informan lokal yang memiliki kontribusi dalam memasok pengetahuan tentang bangsa jajahan bagi pihak kolonial. Kajian ini menunjukkan bahwa Haji Hasan Mustapa tidak sekedar berkedudukan sebagai informan bagi Snouck, tetapi memiliki hubungan persahabatan yang mendalam sejak pertama kali bertemu hingga meninggal dunia. Snouck memandang Mustapa sebagai sosok yang memiliki watak dan bakat yang langka serta mencapai pengetahuan tinggi tentang syariat Islam dan adat-istiadat Sunda. Sebaliknya, Mustapa memandang Snouck sebagai sahabat dekat yang memiliki komitmen untuk saling membela di kala dekat maupun jauh. Mustapa menumpahkan pandangan dan kerinduan dirinya untuk selalu bertemu dengannya. Bahkan Mustapa seringkali meneteskan air mata ketika mengingat masamasa kebersamaannya yang tidak akan terlupakan sepanjang hidupnya. Sebuah persahabatan yang tidak lagi sebatas relasi patron-klien, majikan dan bawahan, tetapi sudah merasuk sedemikian dalam ke dalam ikatan persaudaraan sejati dan kekeluargaan.

\section{CATATAN AKHIR}

1 Kevin W. Fogg, "Seeking Arabs but Looking at Indonesians: Snouck Hurgronje's Arab Lens on the Dutch East Indies," Journal of Middle Eastern and Islamic Studies (in Asia), Vol. 8, No. 1, 2014, hlm. 52.

2 Jan Just Witkam, "Christiaan Snouck Hurgronje," dalam Coeli Fitzpatrick \& Dwayne A. Tunstall (ed.), Orientalist Writers, Dictionary of Literary Biography, vol. 366, (Detroit, etc.: Gale, 2012); Jan Just Witkam, "Christiaan Snouck Hurgronje. A tour d'horizon of his life and work', in Arnoud Vrolijk \& Hans van de Velde, Christiaan Snouck Hurgronje (1857-1936), Orientalist, (Leiden: Leiden University Library, 2007).

3 Karel Steenbrink, Kawan dalam Pertikaian: Kaum Kolonial Belanda dan Islam di Indonesia 1596-1942, terj. Suryan A Jamrah, (Bandung: Mizan, 1995); Aqib Suminto, Politik Islam Hindia Belanda, (Jakarta: LP3ES, 1996), cet. ke-3, hlm. 115-125.

4 Harry J. Benda, Bulan Sabit dan Matahari Terbit, terj. Daniel Dhakidae, Jakarta: Pustaka Jaya, 1980, hlm. 41.

5 Paul van 'T Veer, Perang Aceh, Kisah Kegagalan Snouck Hurgronje, terj. Grafitipers, (Jakarta: Grafiti Pers, 1985); Willem Frederick Wertheim, "Counterinsurgency Research at the Turn of the Century: Snouck Hurgronje and the Acheh War," Sosiologische Gidz, 19 (1972): 320-328.

6 Michael F. Laffan, "Raden Aboe Bakar, An Introductory Note Concerning Snouck Hurgronje's Informant in Jeddah (1884-1912),” Bijdragen tot de Taal-, 
Land-en Volkenkunde, 155 (1999), No: 4, Leiden, hlm. 524.

7 PH. S. van Ronkel, "Aanteekeningen over Islam en Folklore in West-en Midden Java," Bijdragen tot de Taal, Land-en Volkenkunde, 101 (1942), hlm. 311-339.

8 Azyumardi Azra, "Hadhrami Scholars in the Malay-Indonesian Diaspora: A Preliminary Study of Sayyid Uthman," Studia Islamika, Vol. 2, Number 2, 1995, hlm. 14; Nico Kaptein, "Sayyid Uthman On the Legal Validity of Documentary Evidence,” Bijdragen tot de Taal-, Land-en Volkenkunde 153 (1997), no: 1, Leiden, p. 85-102; Nico J.G. Kaptein, "Grateful to the Dutch Government, Sayyid Uthman and Sarekat Islam in 1913,” dalam Anthony Reid dan Michael Gilsenan ed., Islamic Legitimacy in a Plural Asia, (New York: Routledge, 2008), hlm. 98-116.

9 P.Sj. van Koningsveld, "Pengantar: Nasihat-nasihat Snouck sebagai Sumber Sejarah Zaman Penjajahan,” dalam E. Gobee dan C. Adriaanse, Nasihat-nasihat C. Snouck Hurgronje Semasa Kepegawaiannya kepada Pemerintahan Hindia Belanda 1889-1936, Seri Khusus INIS Jilid 1, terj. Sukarsi, (Jakarta: INIS, 1990), hlm. LVI-LVII.

10 Michael Francis Laffan, Islamic Nationhood and Colonial Indonesia, The Umma below the Winds, London-New York: Routledge Curzon, 2003, hlm. 82-84; Jajat Burhanudin, "The Dutch Colonial Policy on Islam: Reading the Intellectual Journey of Snouck Hurgronje," Al-Jami'ah: Journal of Islamic Studies, Vol. 52, no. 1 (2014), doi: 10.14421/ajis.2014.521.25-58, hlm. 35.

11 Edward Said, Orientalism, London: Penguin, 1977, hm. 350.

12 G.W.J. Drewes, Snouck Hurgronje en de Islamwetenschap (Leiden, 1957), hlm. 14, seperti dikutip Aqib Suminto, Politik Islam Hindia Belanda, hlm. 117; G. Drewes, "Snouck Hurgronje and the Study of Islam," Bijdragen tot de Taal, Land-en Volkenkunde 113 (1957), no: 1, Leiden, 1-15.

13 Johannes Pedersen, The Scientific Work of Snouck Hurgronje, (Leiden, 1957); J. Brugman, "Snouck Hurgronje's study of Islamic law," dalam W. Otterspeer (ed.), Leiden Oriental Collections 1850-1940, Leiden: E.J. Brill/Universitaire Pers Leiden, 1989, hlm. 82-93.

14 Van der Maaten (1948), van 'T Veer (1969), Benda (1972), Koningsveld (1980), Wertheim (1981), Algadri (1984), Suminto (1985), Brugman (1989), Steenbrink (1993), Laffan (2003, 2011), Jung (2010), van Dijk (2010), Burhanudin (2007, 2014), Carvalho 2010, dan Fogg (2014).

15 Arnoud Vrolijk, "Appearances Belie: A Mecca-Centred World Map and a Snouck Hurgronje Photograph from the Leiden University Collections," dalam Luitgard Mols \& Marjo Buitelaar eds., Hajj Global Interactions through Pilgrimage, Sidestone Press, 2015: 213-28.

16 K. van der Maaten, Snouck Hurgronje en de Atjeh Oorlog (Leiden, 1948), 2 Jilid; Paul van 'T Veer, Perang Aceh, Kisah Kegagalan Snouck Hurgronje, hlm. 151-62; Antje Missbach, "The Aceh War (1873-1913) and the Influence of Christiaan Snouck Hurgronje," Aceh: History, Politics and Culture. Ed. Arndt Graf, Susanne Schroter, and Edwin Wieringa. Singapore: Institute of Southeast Asian Studies, 2010: 39-62. 
17 Harry J. Benda, "Christiaan Snouck Hurgronje and the Foundations of Dutch Islamic Policy in Indonesia." The Journal of Modern History Vol. 30 No. 4 (Dec., 1958): 338-347; Karel Steenbrink, Kawan dalam Pertikaian: Kaum Kolonial Belanda dan Islam di Indonesia 1596-1942. terj. Suryan A Jamrah. Bandung: Mizan, 1995; Hamid Algadri, Islam dan Keturunan Arab dalam Pemberontakan Melawan Belanda. Bandung: Mizan, 1996; Aqib Suminto, Politik Islam Hindia Belanda. Jakarta: LP3ES, 1996; Michael F. Laffan, Islamic Nationhood and Colonial Indonesia, The Umma below the Winds. London-New York: Routledge Curzon, 2003; Dietrich Jung, "Islam as a Problem: Dutch Religious Politics in the East Indies," Review of Religious Research, Vol. 51: 3, 2010: 288-31; Michael F. Laffan, The Making of Indonesian Islam: Orientalism and the Narration of a Sufi Past. Princeton \& London, Princeton University Press, 2011; Jajat Burhanudin, "The Dutch Colonial Policy on Islam: Reading the Intellectual Journey of Snouck Hurgronje,” Al-Jami'ah: Journal of Islamic Studies, Vol. 52, no. 1 (2014), doi: 10.14421/ajis.2014.521.25-58; Kevin W. Fogg, "Seeking Arabs but Looking at Indonesians: Snouck Hurgronje's Arab Lens on the Dutch East Indies," Journal of Middle Eastern and Islamic Studies (in Asia), Vol. 8, No. 1 (2014): 5173.

18 Christina Carvalho, Christiaan Snouck Hurgronje: Biography and Perception, MA Thesis, Universiteit van Amsterdam, 2010, hlm. 92; Kees van Dijk, "The Elitist Premises of Snouck Hurgronje's Association Fantasy," Studia Islamika, Vol. 17, No. 3, 2010: 407-40.

19 Michael F. Laffan, Islamic Nationhood and Colonial Indonesia, hlm.77-102; Michael F. Laffan, The Making of Indonesian Islam, 147-61.

20 Harry J. Benda, "Christiaan Snouck Hurgronje and the Foundations of Dutch Islamic Policy in Indonesia,” The Journal of Modern History, Vol. 30, No. 4. (Dec., 1958), hlm. 340-341; Deliar Noer, Gerakan Moderen Islam di Indonesia 1900-1942, (Jakarta: LP3ES, 1996), cet. ke-8, hlm. 30-31.

21 Peter Carey, The Power of Prophecy, Prince Dipanagara and the End of an Old Order in Java, 1785-1855, (Leiden: KITLV Press, 2008); Nancy K. Florida, Writing the Past, Inscribing the Future: History as Prophecy in Colonial Java, (Durham and London: Duke University Press, 1995); Paul van 'T Veer, Perang Aceh, Kisah Kegagalan Snouck Hurgronje, terj. Grafitipers, (1985); Willem Frederick Wertheim, "Counterinsurgency Research at the Turn of the Century: Snouck Hurgronje and the Acheh War," Sosiologische Gidz, 19 (1972): 320-328; Sartono Kartodirdjo, Pemberontakan Petani di Banten 1888, Jakarta: Pustaka Jaya, 1984.

22 Karel Steenbrink, Kawan dalam Pertikaian (1995); Harry J. Benda, Bulan Sabit dan Matahari Terbit, hlm. 44.

23 Robert van Niel, "Notes Christian Snouck Hurgronje In Memory of the Centennial of His Birth," The Journal of Asian Studies (pre-1986), vol. 6, No. 4, (Aug 1957), hlm. 593.

24 Pertemuan Mustapa dan Snouck di Mekah sempat menjadi bahan pembicaraan di kalangan sarjana. Ajip Rosidi dan Jajang Jahroni pernah meragukan pertemuan ini. Ajip Rosidi, Haji Hasan Mustapa jeung Karya- 
karyana, Bandung: Pustaka, 1989, hlm. 54; Jajang Jahroni, "The Life and Mystical Thought of Haji Hasan Mustafa (1852-1930),” Thesis, Leiden University, 1999, hlm. 22.

25 Haji Hasan Moestapa, Arabic Letters from Bandung (Correspondence with Snouck Hurgronje), 1911-1923, Cod. Or. 8952 dan Cod. Or. 18.097, UB Leiden University.

26 Hamid Algadri, Islam dan Keturunan Arab dalam Pemberontakan Melawan Belanda, Bandung: Mizan, 1996, hlm. 134.

27 P.Sj. van Koningsveld, Snouck Hurgronje dan Islam, Delapan Karangan tentang Hidup dan Karya Seorang Orientalis Zaman Kolonial (Bandung: Girimukti Pasaka, 1989), hlm. 162 dan 221.

28 PH. S. van Ronkel, "Aanteekeningen over Islam en Folklore in West-en Midden Java," hlm. 311.

29 Michael Laffan, The Makings of Indonesian Islam, Orientalism and the Narration of a Sufi Past, Princeton: Princeton University Press, 2011, hlm. 155. Haji Hasan Mustapa, Gendingan Dangding Sunda Birahi Katut Wirahmana Djilid A, Bandung: Jajasan Kudjang, 1976, hlm. 49.

30 Haji Hasan Moestapa, Bab Adat ${ }^{2}$ Oerang Priangan Djeung Oerang Soenda Lian ti Eta, Ditjitakna di kantor tjitak Kangdjeng Goepernemen di nagara Batawi, 1913, hlm. 194.

31 Michael Laffan, The Makings of Indonesian Islam, hlm. 149; Michael Laffan, "New Turn to Mecca," Revue des mondes musulmans et de la Mediterrranee [online] 124, Noovember 2008, Online since 09 December 2011, connection on 21 April 2013. URL: http://remmm.revues.org/6022

32 Tentang kedudukan penghulu era kolonial, lihat Muhamad Hisyam, Caught between Three Fires: The Javanese Pangulu under The Dutch Colonial Administration 1882-1942, (Jakarta: INIS, 2001); Ibnu Qoyim Isma'il, Kiai Penghulu Jawa Peranannya di Masa Kolonial, (Jakarta: GIP, 1997).

33 Mustapa misalnya menginformasikan perkembangan sejumlah tarekat di Jawa dalam salah satu suratnya pada Snouck di Belanda. Lihat Haji Hasan Moestapa, Arabic Letters from Bandung (Correspondence with Snouck Hurgronje), 1911-1923, Cod. Or. 8952, 21 September 1907, UB Leiden University.

34 Sartono Kartodirdjo, Pemberontakan Petani Banten 1888, terj. Hasan Basari, Jakarta: Pustaka Jaya, 1984.

35 Michael Laffan, The Makings of Indonesian Islam, hlm. 156; C. Snouck Hurgronje, The Achehnese, 2 Volumes, Leiden: Brill, 1906.

36 Jajat Burhanudin, Ulama E Kekuasaan: Pergumulan Elite Muslim dalam Sejarah Indonesia (Bandung: Mizan, 2012), hlm. 158; Mikihiro Moriyama, Semangat Baru: Kolonialisme, Budaya Cetak dan Kesastraan Sunda Abad ke-19, terj. Suryadi, (Jakarta: KPG, 2005), hlm. 149-153.

37 Nina H. Lubis, Kehidupan Menak Priangan 1800-1942, (Bandung: Pusat Informasi Kebudayaan Sunda, 1998), hlm. 24 dan 289.

38 Ajip Rosidi, Mencari Sosok Manusia Sunda, Jakarta: Pustaka Jaya, 2010, hlm. 70. 
39 Mufti Ali, "A Study of Hasan Mustafa's Fatwa: It is Incumbent upon the Indonesian Muslims to be Loyal to the Dutch East Indies Government," Journal of the Pakistan Historical Society, April 2004, Vol. 52 Issue 2, hlm. 91-122.

40 P.Sj. van Koningsveld, Snouck Hurgronje dan Islam, hlm. 28; Jan Just Witkam, “Christiaan Snouck Hurgronje," dalam Coeli Fitzpatrick \& Dwayne A. Tunstall (ed.), Orientalist Writers, Dictionary of Literary Biography, vol. 366, (Detroit, etc.: Gale, 2012), hlm. 151; Jan Just Witkam, "Christiaan Snouck Hurgronje. A tour d'horizon of his life and work', hlm. 27.

41 P.Sj. van Koningsveld, "Pengantar: Nasihat-nasihat Snouck sebagai Sumber Sejarah Zaman Penjajahan," hlm. LI.

42 Edi S. Ekadjati, Naskah Sunda: Inventarisasi dan Pencatatan, Bandung: Lembaga Penelitian Unpad-The Toyota Foundation, 1988, hlm. 284.

43 Haji Hasan Moestapa, Bab Adat ${ }^{2}$ Oerang Priangan Djeung Oerang Soenda Lian ti Eta, Ditjitakna di kantor tjitak Kangdjeng Goepernemen di nagara Batawi, 1913.

44 Hadji Hasan Moestapa, Over de Gewoonten en Gebruiken der Soendaneezen, uit het Soendaasch vertaald en van aanteekeningen voorzien door R.A. Kern, SG Ravenhage, Martinus Nijhoff, 1946.

45 Haji Hasan Mustapa, Adat Istiadat Sunda, penerjemah M. Maryati Sastrawijaya, Bandung: P.T. Alumni, 1985.

46 H. Hasan Moestapa, Boekoe Leutik Djadi Pertelaan Adatna Djalma² di Pasoendan, Lembana Wignjadisastra, Administratrice Tjahaja Pasoendan Bandoeng, 1916; Ajip Rosidi, Haji Hasan Mustapa jeung Karya-karyana, hlm. 493.

47 C. Snouck Hurgronje, Mekka in the Latter Part of the 19th Century, trans. J.H. Monahan with an introduction by Jan Just Witkam Leiden: Brill, 2007, hlm. 287.

48 P.Sj. van Koningsveld, "Pengantar: Nasihat-nasihat Snouck sebagai Sumber Sejarah Zaman Penjajahan,” hlm. LI.

49 Ajip Rosidi, Haji Hasan Mustapa jeung Karya-karyana, hlm. 49.

50 Tentang perselisihan antara Mustapa dan pejabat kolonial terutama asisten residen di Aceh yang membuatnya tidak betah, sempat terserang sakit demam dan segera meninggalkan Aceh, lihat P.Sj. van Koningsveld, "Pengantar: Nasihat-nasihat Snouck sebagai Sumber Sejarah Zaman Penjajahan,” hlm. LII

51 Haji Hasan Moestapa, Arabic Letters from Bandung (Correspondence with Snouck Hurgronje), 1911-1923, Cod. Or. 8952, 13 September 1912, UB Leiden University.

52 Haji Hasan Moestapa, Arabic Letters from Bandung (Correspondence with Snouck Hurgronje), 1911-1923, Cod. Or. 8952, 29 Maret 1912, UB Leiden University.

53 Haji Hasan Moestapa, Arabic Letters from Bandung (Correspondence with Snouck Hurgronje), 1911-1923, Cod. Or. 8952, 1 Januari 1911, UB Leiden University.

54 Haji Hasan Moestapa, Arabic Letters from Bandung (Correspondence with Snouck Hurgronje), 1911-1923, Cod. Or. 8952, 1 Januari 1911, UB Leiden University.

55 Haji Hasan Moestapa, Arabic Letters from Bandung (Correspondence with Snouck 
Hurgronje), 1911-1923, Cod. Or. 8952, 23 Februari 1911, UB Leiden University.

56 Haji Hasan Moestapa, Arabic Letters from Bandung (Correspondence with Snouck Hurgronje), 1911-1923, Cod. Or. 8952, 27 Januari 1912, UB Leiden University.

57 Haji Hasan Moestapa, Arabic Letters from Bandung (Correspondence with Snouck Hurgronje), 1911-1923, Cod. Or. 8952, 29 Maret 1912, UB Leiden University.

58 Haji Hasan Moestapa, Arabic Letters from Bandung (Correspondence with Snouck Hurgronje), 1911-1923, Cod. Or. 8952, 13 September 1912, UB Leiden University.

59 Haji Hasan Moestapa, Arabic Letters from Bandung (Correspondence with Snouck Hurgronje), 1911-1923, Cod. Or. 8952, 25 Oktober 1913, UB Leiden University.

60 Haji Hasan Moestapa, Arabic Letters from Bandung (Correspondence with Snouck Hurgronje), 1911-1923, Cod. Or. 8952, 12 Agustus 1915, UB Leiden University.

61 Haji Hasan Moestapa, Arabic Letters from Bandung (Correspondence with Snouck Hurgronje), 1911-1923, Cod. Or. 8952, 6 Mei 1916, UB Leiden University.

62 Haji Hasan Moestapa, Arabic Letters from Bandung (Correspondence with Snouck Hurgronje), 1911-1923, Cod. Or. 8952, 21 Juli 1917, UB Leiden University.

\section{DAFTAR PUSTAKA}

Algadri, Hamid. 1996. Islam dan Keturunan Arab dalam Pemberontakan Melawan Belanda, Bandung: Mizan.

Ali, Mufti. 2004. "A Study of Hasan Mustafa's Fatwa: It is Incumbent upon the Indonesian Muslims to be Loyal to the Dutch East Indies Government," Journal of the Pakistan Historical Society, Vol. 52 Issue 2, 91-122.

Azra, Azyumardi. 1995. "Hadhrami Scholars in the Malay-Indonesian Diaspora: A Preliminary Study of Sayyid Uthman,” Studia Islamika, Vol. 2, Number 2.

Benda, Harry J. 1958. "Christiaan Snouck Hurgronje and the Foundations of Dutch Islamic Policy in Indonesia," The Journal of Modern History, Vol. 30, No. 4.

1980. Bulan Sabit dan Matahari Terbit, terj. Daniel Dhakidae, Jakarta: Pustaka Jaya.

Brugman, J. 1989. “Snouck Hurgronje’s study of Islamic law,” dalam W. Otterspeer (ed.), Leiden Oriental Collections 1850-1940, Leiden: E.J. Brill/Universitaire Pers Leiden: 82-93.

Burhanudin, Jajat. 2012. Ulama Ë Kekuasaan: Pergumulan Elite Muslim dalam Sejarah Indonesia, Bandung: Mizan.

2014. "The Dutch Colonial Policy on Islam: Reading the Intellectual Journey of Snouck Hurgronje," Al-Jami'ah: Journal of Islamic Studies, Vol. 52, no. 1, doi: 10.14421/ajis.2014.521.25-58.

Carey, Peter. 2008. The Power of Prophecy, Prince Dipanagara and the End of an Old Order in Java, 1785-1855, Leiden: KITLV Press. 
Carvalho, Christina. 2010. Christiaan Snouck Hurgronje: Biography and Perception, MA Thesis, Universiteit van Amsterdam.

Drewes, G. 1957. "Snouck Hurgronje and the Study of Islam," Bijdragen tot de Taal, Land- en Volkenkunde 113, no: 1, Leiden, 1-15.

Ekadjati, Edi S. 1988. Naskah Sunda: Inventarisasi dan Pencatatan, Bandung: Lembaga Penelitian Unpad-The Toyota Foundation.

Florida, Nancy K. 1995. Writing the Past, Inscribing the Future: History as Prophecy in Colonial Java, Durham and London: Duke University Press.

Fogg, Kevin W. 2014. "Seeking Arabs but Looking at Indonesians: Snouck Hurgronje's Arab Lens on the Dutch East Indies," Journal of Middle Eastern and Islamic Studies (in Asia), Vol. 8, No. 1.

Hisyam, Muhamad. 2001. Caught between Three Fires: The Javanese Pangulu under The Dutch Colonial Administration 1882-1942, Jakarta: INIS.

Hurgronje, C. Snouck. 1906. The Achehnese, 2 Volumes, Leiden: Brill. 2007. Mekka in the Latter Part of the 19th Century, trans. J.H. Monahan with an introduction by Jan Just Witkam Leiden: Brill.

Isma'il, Ibnu Qoyim. 1997. Kiai Penghulu Jawa Peranannya di Masa Kolonial, Jakarta: GIP.

Jahroni, Jajang. 1999. "The Life and Mystical Thought of Haji Hasan Mustafa (1852-1930)," Thesis, Leiden University.

Jung, Dietrich. 2010. "Islam as a Problem: Dutch Religious Politics in the East Indies," Review of Religious Research, Vol. 51: 3, 288-31.

Kaptein, Nico. 1997. "Sayyid Uthman On the Legal Validity of Documentary Evidence," Bijdragen tot de Taal-, Land-en Volkenkunde 153, no: 1, Leiden, 85 102.

2008. "Grateful to the Dutch Government, Sayyid Uthman and Sarekat Islam in 1913," dalam Anthony Reid dan Michael Gilsenan ed., Islamic Legitimacy in a Plural Asia, New York: Routledge: 98-116.

Kartodirdjo, Sartono. 1984. Pemberontakan Petani di Banten 1888, Jakarta: Pustaka Jaya.

Laffan, Michael F. 1999. "Raden Aboe Bakar, An Introductory Note Concerning Snouck Hurgronje's Informant in Jeddah (1884-1912),” Bijdragen tot de Taal, Land-en Volkenkunde, 155, No: 4, Leiden.

.2003. Islamic Nationhood and Colonial Indonesia, The Umma below the Winds, London-New York: Routledge Curzon.

2008. "New Turn to Mecca," Revue des mondes musulmans et de la Mediterrranee [online] 124, Online since 09 December 2011, connection on 21 April 2013. URL: http://remmm.revues.org/6022

2011. The Makings of Indonesian Islam, Orientalism and the Narration of a Sufi Past, Princeton: Princeton University Press.

Lubis, Nina H. 1998. Kehidupan Menak Priangan 1800-1942, Bandung: Pusat Informasi Kebudayaan Sunda.

Missbach, Antje. 2010. "The Aceh War (1873-1913) and the Influence of Christiaan Snouck Hurgronje,” Aceh: History, Politics and Culture. Ed. Arndt 
Graf, Susanne Schroter, and Edwin Wieringa. Singapore: Institute of Southeast Asian Studies, 39-62.

Moestapa, Haji Hasan. 1913. Bab Adat ${ }^{2}$ Oerang Priangan Djeung Oerang Soenda Lian ti Eta, Ditjitakna di kantor tjitak Kangdjeng Goepernemen di nagara Batawi.

, 1916, Boekoe Leutik Djadi Pertelaan Adatna Djalma² di Pasoendan, Lembana Wignjadisastra, Administratrice Tjahaja Pasoendan Bandoeng.

, 1946, Over de Gewoonten en Gebruiken der Soendaneezen, uit het Soendaasch vertaald en van aanteekeningen voorzien door R.A. Kern, S-G Ravenhage, Martinus Nijhoff.

1911-1923. Arabic Letters from Bandung (Correspondence with Snouck Hurgronje), Cod. Or. 18.097, UB Leiden University.

Arabic Letters from Bandung (Correspondence with Snouck Hurgronje), 1911-

1923, Cod. Or. 8952, 13 September 1912, UB Leiden University. Arabic Letters from Bandung (Correspondence with Snouck Hurgronje), 1911-

1923, Cod. Or. 8952, 29 Maret 1912, UB Leiden University. Arabic Letters from Bandung (Correspondence with Snouck Hurgronje), 1911.

1923, Cod. Or. 8952, 1 Januari 1911, UB Leiden University.

. Arabic Letters from Bandung (Correspondence with Snouck Hurgronje), $1911-$

1923, Cod. Or. 8952, 23 Februari 1911, UB Leiden University.

Arabic Letters from Bandung (Correspondence with Snouck Hurgronje), 1911-

1923, Cod. Or. 8952, 27 Januari 1912, UB Leiden University. Arabic Letters from Bandung (Correspondence with Snouck Hurgronje), 1911-

1923, Cod. Or. 8952, 29 Maret 1912, UB Leiden University. Arabic Letters from Bandung (Correspondence with Snouck Hurgronje), 1911-

1923, Cod. Or. 8952, 13 September 1912, UB Leiden University.

. Arabic Letters from Bandung (Correspondence with Snouck Hurgronje), 1911-

1923, Cod. Or. 8952, 25 Oktober 1913, UB Leiden University. . Arabic Letters from Bandung (Correspondence with Snouck Hurgronje), 1911-

1923, Cod. Or. 8952, 12 Agustus 1915, UB Leiden University. Arabic Letters from Bandung (Correspondence with Snouck Hurgronje), 19111923, Cod. Or. 8952, 6 Mei 1916, UB Leiden University.

. Arabic Letters from Bandung (Correspondence with Snouck Hurgronje), $1911-$

1923, Cod. Or. 8952, 21 Juli 1917, UB Leiden University.

Arabic Letters from Bandung (Correspondence with Snouck Hurgronje), 1911-

1923, Cod. Or. 8952, 21 September 1907, UB Leiden University.

Moriyama, Mikihiro. 2005. Semangat Baru: Kolonialisme, Budaya Cetak dan Kesastraan Sunda Abad ke-19, terj. Suryadi, Jakarta: KPG.

Mustapa, Haji Hasan. 1976. Gendingan Dangding Sunda Birahi Katut Wirahmana Djilid A, Bandung: Jajasan Kudjang.

., 1985, Adat Istiadat Sunda, penerjemah M. Maryati Sastrawijaya, Bandung:

P.T. Alumni.

Noer, Deliar. 1996. Gerakan Moderen Islam di Indonesia 1900-1942, Jakarta: LP3ES, cet. ke-8. 
Pedersen, Johannes. 1957. The Scientific Work of Snouck Hurgronje, (Leiden). Rosidi, Ajip. 1989. Haji Hasan Mustapa jeung Karya-karyana, Bandung: Pustaka. 2010. Mencari Sosok Manusia Sunda, Jakarta: Pustaka Jaya.

Said, Edward. 1977. Orientalism, London: Penguin.

Steenbrink, Karel. 1995. Kawan dalam Pertikaian: Kaum Kolonial Belanda dan Islam di Indonesia 1596-1942, terj. Suryan A Jamrah, Bandung: Mizan.

Suminto, Aqib. 1996. Politik Islam Hindia Belanda, Jakarta: LP3ES, cet. ke-3.

van der Maaten, K. 1948. Snouck Hurgronje en de Atjeh Oorlog, Leiden, 2 Jilid.

van Dijk, Kees. 2010. "The Elitist Premises of Snouck Hurgronje's Association Fantasy," Studia Islamika, Vol. 17, No. 3, 407-40.

van Koningsveld, P.Sj. 1990. "Pengantar: Nasihat-nasihat Snouck sebagai Sumber

Sejarah Zaman Penjajahan,” dalam E. Gobee dan C. Adriaanse, Nasihat-nasihat

C. Snouck Hurgronje Semasa Kepegawaiannya kepada Pemerintahan Hindia Belanda 1889-1936, Seri Khusus INIS Jilid 1, terj. Sukarsi, Jakarta: INIS.

1989. Snouck Hurgronje dan Islam, Delapan Karangan tentang Hidup dan Karya Seorang Orientalis Zaman Kolonial, Bandung: Girimukti Pasaka.

van Niel, Robert. 1957. "Notes Christian Snouck Hurgronje In Memory of the Centennial of His Birth,” The Journal of Asian Studies (pre-1986), vol. 6, No. 4. van Ronkel, PH. S. 1942. "Aanteekeningen over Islam en Folklore in West-en Midden Java," Bijdragen tot de Taal, Land-en Volkenkunde, 101: 311-339.

van 'T Veer, Paul. 1985. Perang Aceh, Kisah Kegagalan Snouck Hurgronje, terj. Grafitipers, Jakarta: Grafiti Pers.

Vrolijk, Arnoud. 2015. "Appearances Belie: A Mecca-Centred World Map and a Snouck Hurgronje Photograph from the Leiden University Collections," dalam Luitgard Mols \& Marjo Buitelaar eds., Hajj Global Interactions through Pilgrimage, Sidestone Press, 213-28.

Witkam, Jan Just. 2007. “Christiaan Snouck Hurgronje. A tour d'horizon of his life and work', in Arnoud Vrolijk \& Hans van de Velde, Christiaan Snouck Hurgronje (1857-1936), Orientalist, Leiden: Leiden University Library. . 2012. "Christiaan Snouck Hurgronje," dalam Coeli Fitzpatrick \& Dwayne A. Tunstall (ed.), Orientalist Writers, Dictionary of Literary Biography, vol. 366, Detroit, etc.: Gale.

Wertheim, Willem Frederick. 1972. "Counterinsurgency Research at the Turn of the Century: Snouck Hurgronje and the Acheh War," Sosiologische Gidz, 19: $320-328$. 